OPEN ACCESS

Edited by:

Ruoli Chen,

Keele University, United Kingdom

Reviewed by:

Aaron Sathyanesan,

Children's National Health System,

United States

Tommaso Angelone,

Università della Calabria, Italy

*Correspondence:

Arshad Majid

arshad.majid@sheffield.ac.uk

G. K. Rajanikant

rajanikant@nitc.ac.in

Specialty section:

This article was submitted to

Cellular Biochemistry,

a section of the journal

Frontiers in Cell and Developmental

Biology

Received: 12 September 2018

Accepted: 10 December 2018

Published: 08 January 2019

Citation:

Davis CK, Jain SA, Bae O-N, Majid A and Rajanikant GK (2019)

Hypoxia Mimetic Agents for Ischemic

Stroke. Front. Cell Dev. Biol. 6:175.

doi: 10.3389/fcell.2018.00175

\section{Hypoxia Mimetic Agents for Ischemic Stroke}

\author{
Charles K. Davis ${ }^{1}$, Saurabh A. Jain ${ }^{2}$, Ok-Nam Bae ${ }^{3}$, Arshad Majid ${ }^{2 *}$ and \\ G. K. Rajanikant ${ }^{1 *}$
}

${ }^{1}$ School of Biotechnology, National Institute of Technology Calicut, Calicut, India, ${ }^{2}$ Sheffield Institute for Translational Neuroscience, University of Sheffield, Sheffield, United Kingdom, ${ }^{3}$ College of Pharmacy, Hanyang University, Ansan, South Korea

Every year stroke claims more than 6 million lives worldwide. The majority of them are ischemic stroke. Small molecule-based therapeutics for ischemic stroke has attracted a lot of attention, but none has been shown to be clinically useful so far. Hypoxiainducible factor-1 (HIF-1) plays a crucial role in the transcriptional adaptation of cells to hypoxia. Small molecule-based hypoxia-mimetic agents either stabilize HIF-1 $\alpha$ via HIFprolyl hydroxylases (PHDs) inhibition or through other mechanisms. In both the cases, these agents have been shown to confer ischemic neuroprotection in vitro and in vivo. The agents which act via PHD inhibition are mainly classified into iron chelators, iron competitors, and 2 oxoglutarate (2OG) analogs. This review discusses HIF structure and key players in the HIF-1 degradation pathway as well as the genes, proteins and chemical molecules that are connected to HIF-1 and how they affect cell survival following ischemic injury. Furthermore, this review gives a summary of studies that used PHD inhibitors and other HIF-1 $\alpha$ stabilizers as hypoxia-mimetic agents for the treatment of ischemic injury.

Keywords: hypoxia-inducible factor-1, ischemic stroke, neuroprotection, iron chelators, hypoxia mimetic agent

\section{INTRODUCTION}

HIF-1 is a transcription factor that acts as a master regulator of $\mathrm{O}_{2}$ homeostasis (Semenza, 1998). It modulates the expression of an array of genes (Figure 1), and many of them are involved in the cellular adaptation to hypoxia (Semenza, 2001). Vascular endothelial growth factor (VEGF), Erythropoietin (EPO), glucose transporter 1 (GLUT1), heme oxygenase 1 (HO-1), and endothelial nitric oxide (eNOS) synthase are some of the genes that are directly involved in HIF-1 mediated cellular response to hypoxia (Schofield and Ratcliffe, 2004). As HIF-1 stabilization is an endogenous cellular mechanism to reduce hypoxia-induced injury, it is hypothesized that pre and post-hypoxic stabilization of HIF-1 by external means can enhance protection (Shi, 2009). Among these foreign interventions, the small molecule-based HIF-1 stabilization is widely studied and has shown promising results (Siddiq et al., 2005). Most of the small-molecules used for this purpose either mimic or compete with the co-factors or co-substrates of HIF-1 degradation pathway. The small molecules that are used to stabilize HIF- $1 \alpha$ are widely known as hypoxia-mimetic agents. Some of the familiar hypoxia-mimetic agents are desferrioxamine (DFO) and cobalt chloride $\left(\mathrm{CoCl}_{2}\right)$ (Zeng et al., 2011). Apart from these small molecules, there are newly found mRNAs and other compounds which stabilize HIF-1 $\alpha$. In this review, we discuss the small chemical molecules and other biological compounds that have conferred protection against ischemic stroke injury via HIF-1 pathway stabilization. 


\section{HIF STRUCTURE AND PATHWAY}

Hypoxia-inducible factor belongs to the PAS family (PER-ARNTSIM), and functionally active HIF consists of two basic helixloop-helix (bHLH) protein subunits, alpha and beta/ARNT (aryl hydrocarbon receptor nuclear translocator). Apart from bHLH, N-terminal half of HIFs composed of Per-ARNT-Sim (PAS) homology domains. The bHLH and PAS regions are involved in the heterodimerization and DNA binding, respectively. The terminal-transactivation domains (TADs) are present in the C-terminal region of HIF, and they control the transcriptional activity of the protein (Figure 2) (Beaudry et al., 2016).

The alpha subunit of HIF has three isoforms, HIF- $1 \alpha$, HIF- $2 \alpha$, and HIF-3 $\alpha$. Likewise, the beta subunit has three isoforms, ARNT, ARNT2, and ARNT3 (Semenza, 2000). The HIF-1 $\alpha / \beta$ dimer controls the transcription of genes by binding to a core DNA motif (G/ACGTG) in hypoxia-response elements (HREs). The HIF-1 $\beta$ subunit is constitutively produced in the nucleus whereas the stability of HIF- $1 \alpha$ depends on the availability of oxygen (Vadlapatla et al., 2013). Under hypoxic condition, HIF$1 \alpha$ is stable and transported to the nucleus. However, under the normoxic condition, HIF mediated transcription is inhibited by the HIF prolyl hydroxylases (PHDs) and asparaginyl hydroxylase (FIH). PHD2 hydroxylates the two proline residues (402 and 564 ) on the oxygen-dependent degradation domain (ODDD) of HIF- $1 \alpha$ and makes it susceptible to ubiquitin-mediated proteolysis via von Hippel-Lindau tumour suppressor (pVHL) binding. On the contrary, FIH hydroxylases asparagine residue (803) of HIF- $1 \alpha$ and prevents binding of the transcriptional coactivators (p300/CBP) to HIF-1 $\alpha$ (Figure 3) (Speer et al., 2013). Hydroxylation of HIF $\alpha$ subunit by PHDs is an evolutionarily conserved mechanism of sensing the oxygen concentration inside the cell. Thus, stabilization of HIF- $1 \alpha$ by an exogenous technique may activate transcriptional and posttranscriptional responses that will help the cell to overcome hypoxic damage (Masoud and Li, 2015).

HIF- $1 \alpha$ degradation can be restrained by inhibiting the activity of PHDs and FIH. PHDs and FIH belong to a class of enzymes known as 2-oxoglutarate dependent dioxygenases and are the most prominent known family of non-heme oxidizing enzymes (Schofield and Zhang, 1999). There are three PHD isoforms, PHD1, PHD2 and PHD3. Even though these isoforms have a similar C-terminal catalytic domain, $\mathrm{N}$-terminal sequences differ significantly (Siddiq et al., 2009). mRNA expression analysis revealed that the expression patterns of PHD isoforms are tissuespecific and all the isoforms play a unique role in the regulation of HIF- $1 \alpha$ and HIF-2 $\alpha$ (Appelhoff et al., 2004). Both PHDs and FIH require oxygen, iron $\left(\mathrm{Fe}^{2+}\right)$ and $2 \mathrm{OG}$ for the hydroxylation reaction (Singh et al., 2012).

Hypoxic microenvironments are important in the developing embryo, and they control cellular differentiation. These hypoxic microenvironments prompt the cells to activate HIFs which in turn regulate the development of the blood, vasculature, placenta, nervous system, and other organs (Simon and Keith, 2008). Thus, HIFs have a crucial role in embryonic development and survival. Validating the role of HIF during embryonic development, studies using HIF- $1 \alpha$ deficient mouse embryos stopped developing by day 9 and died by day 10.5 due to extensive cell death and other abnormalities (Semenza, 2014).

\section{THE RELEVANCE OF THE HIF-1 PATHWAY IN ISCHEMIC STROKE}

Cerebral stroke is a significant cause of morbidity and mortality worldwide (Kim and Johnston, 2013). More than $80 \%$ of strokes are ischemic while the remaining is hemorrhagic. Ischemic stroke occurs when a vessel supplying blood to the brain is obstructed due to a thrombus, embolus, or other blockage (Harten et al., 2010). Prevention of neuronal death and improving the recovery following ischemic injury are the central focuses of developing stroke therapeutics. Apart from tissue plasminogen activator (tPA), no drugs are able to confer neuroprotection following ischemic stroke in clinical studies (Shi, 2009).

A large number of preclinical studies that used PHD inhibitors were able to show that the activation of HIF1 can be a potentially attractive way to achieve significant neuroprotection following ischemic injury (Karuppagounder and Ratan, 2012). Apart from stroke, PHD inhibition persistently extended neuroprotection in diverse neurological disease models (Speer et al., 2013). At the same time, a few studies observed adverse effects on brain cells upon treatment with PHD inhibitors mostly because of the activation of pro-death proteins like BNIP3 and NIX (Chen W. et al., 2009). As hypoxia induces HIF-1 $\alpha$ expression, most hypoxia-mimetic agents upregulate HIF- $1 \alpha$ and orchestrate its downstream gene expression (Karuppagounder and Ratan, 2012). Neuroprotection via HIF-1 $\alpha$ stabilization following ischemic stroke is still a controversial topic due to its link to a vast variety of genes that mediate both adaptive and pathological processes (Vangeison et al., 2008). Unlike PHD inhibitors, not many FIH inhibitors are discovered, and the possibility of attaining neuroprotection via FIH inhibition has yet to be fully explored.

The altered expression of HIF-1 and its downstream genes during hypoxia have been very well studied in both in vitro and in vivo models (Semenza, 2001). Several processes like angiogenesis and erythropoiesis are connected to HIF-1 stabilization. Apart from this, recent studies were able to deduce more novel phenomena and genes linked to the HIF-1 pathway (Valsecchi et al., 2011; Liu et al., 2012). In a transient global ischemia model, HIF-1 expression was enhanced as early as $1 \mathrm{~h}$ in the recovery phase, and this enhanced expression lasted for 7 days (Chavez and Lamanna, 2002). Besides, expression of HIF1 regulated genes, EPO and GLUT1 were elevated during the reperfusion period. The above study also found that insulin-like growth factor-1 (IGF-1) was able to induce HIF-1 expression in vitro and in vivo.

HIF- $2 \alpha$ has $48 \%$ structural similarity with HIF- $1 \alpha$, and it also activates HRE-dependent gene transcription ( $\mathrm{Hu}$ et al., 2003). However, HIF- $1 \alpha$ and HIF- $2 \alpha$ have discrete transcriptional targets and perform non-redundant roles. Their expression patterns are tissue specific and the part played by these isoforms in tumor progression is contrasting (Ratcliffe, 2007). A study observed that HIF-1 mediated genes conferred brain 


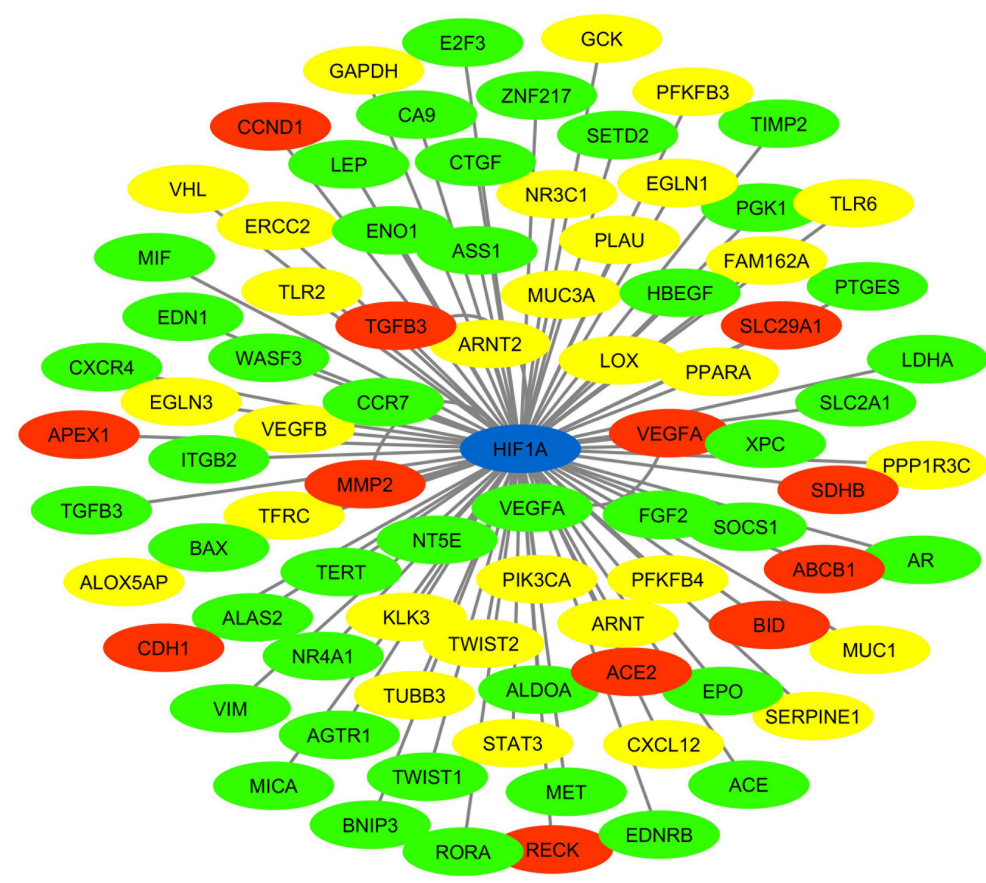

Repression

Activation

Unknown

FIGURE 1 | Network showing HIF-1 connected to its target genes (adapted from: http://www.grnpedia.org/trrust/). Colors inside the shape represent the type of interaction.

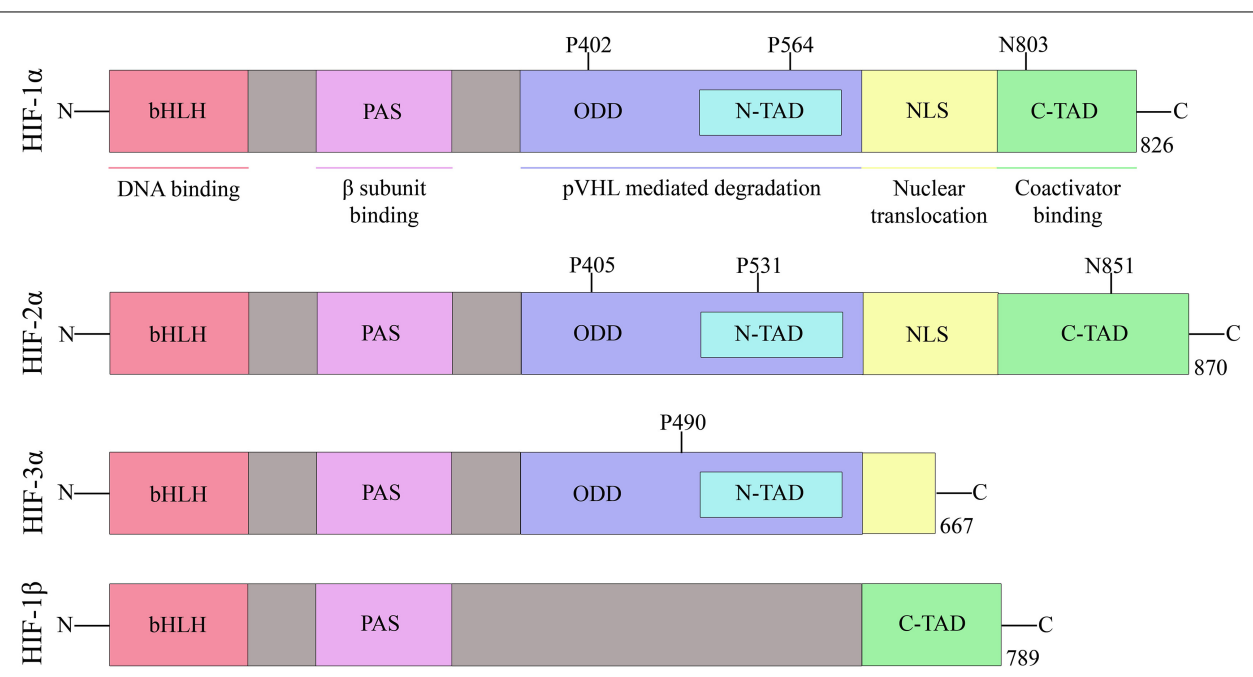

FIGURE 2 | Domain structure of human HIF subunits and isoforms.

hypoxia-induced tolerance rather than HIF-2 regulated genes (Bernaudin et al., 2002). They came to this conclusion as because HIF- $2 \alpha$ levels did not increase significantly in neuronal cells following hypoxia. Further, this study showed that adrenomedullin, propyl 4 -hydroxylase $\alpha$, metallothionein 1 (MT1 ), mitogen-activated protein kinase phosphatase 1(MKP-1), CUGBP Elav-Like Family Member (CELF), 12-lipoxygenase and carbonic anhydrase 1 (CAR-1) are regulated by hypoxia. HIF-1 $\alpha$ was also found to bind to the caspase- 3 gene promoter region specifically. Moreover, HIF- $1 \alpha$ and procaspase- 3 showed similar expression pattern following photothrombotic cerebral ischemia (Hoecke et al., 2007).

Hypoxia-inducible factor responsive genes perform a significant role in the ischemic preconditioning (IPC) induced neuroprotection (Jones and Bergeron, 2001; Valsecchi et al., 2011). Up-regulation of cytochrome P450 2C11 by HIF- $1 \alpha$ has a role in the tolerance induced by hypoxic preconditioning (HPC) in astrocytes (Liu and Alkayed, 2005). 2-methoxyestradiol (2ME2) is a metabolite of estrogen and an inhibitor of HIF- $1 \alpha$ (Zhou et al., 2008). A study by Zhou and co-workers showed that 


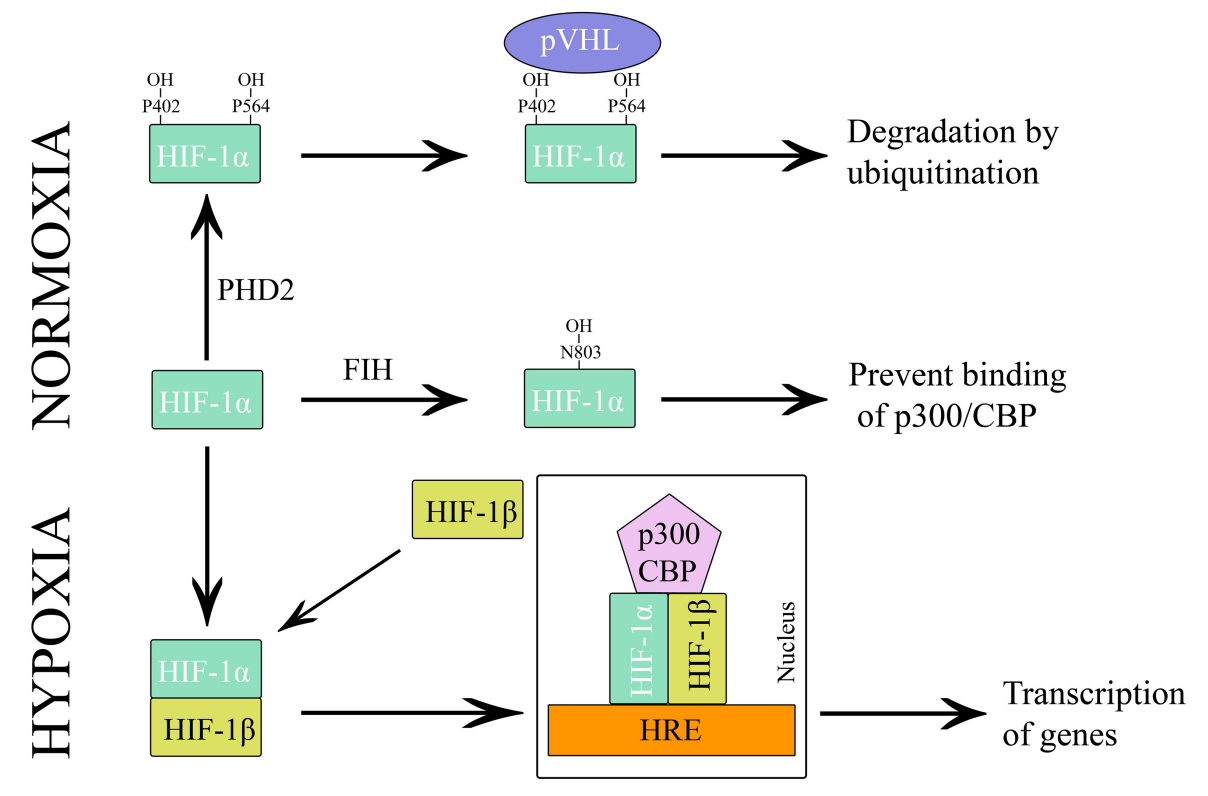

FIGURE 3 | Regulation of HIF-1 during hypoxia and normoxia.

2ME2 aggravated the CA1 hippocampal cell death after global ischemia in rats (Zhou et al., 2008). Glucose at a concentration of $25 \mathrm{mM}$ up-regulated the expression of HIF-1 $\alpha$ in rat primary cortical neurons exposed to hypoxia. Surprisingly, the study showed that along with hypoxia, a reducing environment is required for the stabilization of HIF- $1 \alpha$ in neuronal cells (Guo et al., 2008). The above lab also found out that BCL2 interacting protein 3 (BNIP3) and BCL2 interacting protein 3 like (NIX/BNIP3L) play a role in the HIF- $1 \alpha$ mediated neuroprotection during ischemia-reperfusion (Guo, 2017).

Sodium-calcium exchanger-1 (NCX1) helps in the maintenance of $\mathrm{Na}^{+}$and $\mathrm{Ca}^{2+}$ homeostasis (Michel et al., 2014). In a recent study, it was demonstrated that NCX1 gene is controlled by HIF-1 and contributes to the HIF-1 mediated neuroprotection during brain preconditioning (Valsecchi et al., 2011). The mammalian target of rapamycin (mTOR) belongs to a lipid kinases family, and it is involved in cell growth, survival, and proliferation (Yoon, 2017). mTOR facilitated neuroprotection under ischemic conditions through the activation of HIF-1 $\alpha$, and by the regulation of VEGF expression and neuronal apoptosis in developing rat brain (Chen et al., 2012).

A few studies showed that deletion of PHD2 in neuronal cells has beneficial effects like improvement in histological and functional outcomes and neovascularisation through the promotion of HIF-VEGF axis (Li et al., 2016). Supporting this observation, knockdown of HIF-1 $\alpha$ before oxidative stress aggravated the impairment of learning and memory in rat model (Yang et al., 2017).

The effect of HIF-1 $\alpha$ stabilization is not much studied in glial cells as in neurons. In a study by Vangeison et al. (2008) explored the impact of knocking down HIF-1 $\alpha$ specifically in astrocytes in neuron/astrocyte co-cultures exposed to hypoxia. Selective deletion of HIF- $1 \alpha$ in astrocytes significantly protected neurons from hypoxia-induced neuronal death in co-cultures. Myeloid-specific knockout (KO) of HIF-1 $\alpha$ resulted in faster behavioral recovery of mice subjected to MCAO (Bok et al., 2017). The HIF- $1 \alpha \mathrm{KO}$ mice had fewer infiltrating microglia and apoptotic neurons in the hippocampus following MCAO compared to its wild-type counterpart. The above group also observed that HIF-1 $\alpha$ governs microglial phagocytosis and production of ROS and TNF- $\alpha$ under ischemic conditions. Sirtuin 1 (Sirt 1) has many vital roles in response to metabolic stress, especially cerebral ischemia (Koronowski and PerezPinzon, 2015). A study by Jablonska et al. (2016) observed that the presence of HIF- $1 \alpha$ plays an essential role in hypoxia-induced Sirtl expression in oligodendrocyte progenitor cell (OPC).

\section{The Pro and Anti-apoptotic Face of HIF-1 $\alpha$ Stabilization in Ischemic Stroke}

HIF-1 has both pro and anti-apoptotic features. It improved the expression of genes like EPO and VEGF that are linked to several pathways related to neuroprotection. However, it also participates in the pro-apoptotic process by stabilizing the tumor suppressor protein p53 during severe hypoxia (Fan et al., 2009). Further, it promoted cell necrosis in collaboration with calcium and calpain. It was found to increase blood-brain barrier (BBB) permeability and thus heighten brain oedema.

In agreement with the pro-apoptotic role of HIF-1, a few studies found that HIF-1deficiency can confer neuroprotection against acute hypoxia-induced cell death in mice (Helton et al., 2005). A similar trend was observed in a study by Chen C. et al. (2009) that used HIF-1 $\alpha$ siRNA. The authors showed that HIF- $1 \alpha$ siRNA treatment protected neurons from ischemic injury in vivo through the inhibition of VEGF and apoptosis-related proteins like p53 and Caspase-3 along with HIF-1 $\alpha$. The $c$-glycosylated 
flavone, vitexin (5, 7, 4-trihydroxyflavone-8-glucoside) is a HIF$1 \alpha$ inhibitor (Min et al., 2015). Inhibition of HIF- $1 \alpha$ in the early stages of neonatal cerebral ischemia with vitexin conferred neuroprotection in vivo.

Further, Chen et al. (2008) observed that inhibition of HIF-1 $\alpha$ by $2 \mathrm{ME} 25 \mathrm{~min}$ after the hypoxia-ischemia protected the neuronal cells in the neonatal rat. There was no significant reduction in infarct volume when the treatment with the $2 \mathrm{ME} 2$ was delayed for 3 hrs. HIF-1 inhibition also protected BBB and reduced brain oedema. While, the treatment with HIF-1 $\alpha$ stabilizer DMOG, increased $\mathrm{BBB}$ permeability and brain oedema. Additionally, Barteczek et al. (2016) showed that HIF-1 and HIF-2 are not needed for cell survival under hypoxic conditions. This study also showed that HIF-1/2 deficiency might protect neurons from early neuronal cell death and neurological impairment caused by ischemic stroke.

Additionally, Aminova et al. (2004) showed that the prodeath or anti-death role of HIF-1 $\alpha$ in a cell depends on the type of death stimulus. HIF-1 $\alpha$ overexpressing HT2 2 cells showed increased sensitivity to glutamate toxicity, but they were more resistant to cell death induced by camptothecin or tunicamycin or thapsigargin. When the level of p53 is low, hypoxia-induced HIF- $1 \alpha$ triggers the transcriptional activation of adaptive genes. However, during severe and sustained hypoxia, p53 levels increase along with HIF- $1 \alpha$ stabilization and these proteins together activate pathological genes such as BAX (Halterman et al., 1999).

Tricyclodecan-9-ylxanthogenate (D609) down-regulates HIF$1 \alpha$ similar to 2ME2. Treatment with D609 or 2ME2 reduced infarct volume and improved neuroscore in rats following MCAO (Chen et al., 2007). These HIF-1 $\alpha$ inhibitors decreased the expression of VEGF, BNIP3 and cleaved caspase 3. According to a study carried out by Mayhan (1999), VEGF promoted the BBB permeability via a nitric oxide synthase/cGMPdependent pathway. Since VEGF is directly controlled by HIF-1, the negative effect of HIF- $1 \alpha$ in ischemic stroke may be linked to VEGF. Information from the above studies suggests that the positive or negative effects of HIF-1 depend on cell type and the severity of hypoxia. The nature of ischemic insult also plays a role in determining whether HIF$1 \alpha$ will advocate pro-death or pro-survival pathways (Shi, 2009).

\section{Biphasic Expression Pattern of HIF-1 $\alpha$ Following Ischemic Injury}

Biphasic expression pattern of HIF-1 $\alpha$ was observed in some of the studies following in vitro and in vivo models of cerebral ischemia. A study by Liu et al. (2015) monitored the changes in the HIF-1 $\alpha$ gene and protein expression at different time points in a middle cerebral artery occlusion (MCAO) model using an embolus (eMCAO). HIF-1 $\alpha$ mRNA level gradually increased following ischemia and peaked at $6 \mathrm{~h}$. After that, it slowly decreased and came to a low level at $24 \mathrm{~h}$. A similar pattern of expression was observed from 24 to $168 \mathrm{~h}$ reaching the peak at $72 \mathrm{~h}$. An exactly same trend was seen in the case of HIF- $1 \alpha$ protein expression.
According to a study by Yeh et al. (2010), inhibition of HIF$1 \alpha$ in the early time point ( $0.5 \mathrm{~h}$ after ischemic stress) abated brain injury and oedema. While inhibiting HIF-1 $\alpha$ at a later stage ( $8 \mathrm{~h}$ after ischemic injury) increased brain damage and decreased VEGF expression. Theoretically, HIF-1 $\alpha$ induction at the early time points of ischemia activates apoptotic pathways, and at late time points, it promotes cell survival pathways. Comparable expression pattern of HIF- $1 \alpha$ was observed in other study carried out by Baranova et al. (2007) in the MCAO model.

In neonatal rat brain, upon MCAO, HIF-1 $\alpha$ protein expression was elevated immediately ( $0 \mathrm{~h}$, without reperfusion) and peaked at $8 \mathrm{~h}$, and then deteriorated at $24 \mathrm{~h}$ after reperfusion ( $\mathrm{Mu}$ et al., 2003). VEGF protein expression was also similar to that of HIF-1 $\alpha$. This variation shows the biphasic nature of HIF-1 expression following cerebral ischemia in neonatal brain. When compared to the expression pattern in neuronal cells, similar alterations in expression of HIF- $1 \alpha$ mRNA and protein were observed in microglia cells following exposure to hypoxic conditions (Wang et al., 2017). These studies have enhanced our understanding of the dual and contrasting roles of HIF- $1 \alpha$ expression in neurons following ischemic stroke. To a certain extent, this biphasic expression pattern of HIF- $1 \alpha$ will decide the time window of administration of drugs that act via HIF-1 $\alpha$ stabilization for maximum protection.

\section{HYPOXIA MIMETIC AGENTS IN ISCHEMIC STROKE}

The term "hypoxia mimetic agent" has been widely used to indicate biological or chemical molecules which are used to up-regulate HIF-1 $\alpha$ expression. They do it either via PHDs inhibition or some other mechanisms. Here, in this review, HIF$1 \alpha$ stabilizers are broadly classified according to the involvement of PHDs in the stabilization process.

\section{HIF-1 $\alpha$ Up-Regulation via Inhibition of PHD Pathway}

Most of the HIF-1 $\alpha$ up-regulators act via PHD inhibition. Currently, the following interventions are used stabilize HIF-1 $\alpha$ and mimic hypoxic conditions via PHD inhibition: (a) reduce $\mathrm{Fe}^{2+}$ availability using iron chelators; (b) introduce metal ions that will compete with $\mathrm{Fe}^{2+}$; (c) use 2OG analogs. HIF-1 $\alpha$ stabilizers that do not come under any of the above categories are discussed under a separate subheading.

\section{Iron Chelators and Competitors}

Iron chelators are small molecules that bind very tightly to iron and reduce the amount of free divalent iron available for PHD mediated HIF hydroxylation reaction (Peyssonnaux et al., 2008). Deferoxamine mesylate (DFO) is a widely used iron chelator that removes excess iron from the body (Fisher et al., 2013). Previously, it was thought that iron chelators prevent oxidative injury by obstructing hydroxyl radical formation but later studies revealed that iron chelators inhibit the action of PHDs and upregulate HIF-1 expression (Siddiq et al., 2005). Alternatively, 
iron competitors (mostly divalent metal ions) that compete with $\mathrm{Fe}^{2+}$ in the PHD mediated HIF-1 hydroxylation process can be used. Although there are several iron competitors like $\mathrm{Ni}^{2+}$ and $\mathrm{Mn}^{+}, \mathrm{Co}^{2+}$ in the form of cobalt chloride $\left(\mathrm{CoCl}_{2}\right)$ is the most widely used iron competitor for PHD inhibition (Fandrey et al., 2006). A recent study by $\mathrm{Na}$ et al. (2015) reported that $\mathrm{Zn}^{2+}$ could selectively inhibit PHD3 over PHD2.

A study by Zaman et al. (1999) was one of the first studies to explore HIF-1 mediated neuroprotection by iron chelators following hypoxic stress. In this study, iron chelators, DFO and mimosine (MIM) protected embryonic cortical neurons from glutathione depletion and oxidative stress-induced cell death at a concentration of $100 \mu \mathrm{M}$. Neuroprotective capabilities of these agents were also comparable to their ability to augment DNA binding of HIF-1. These compounds also upregulated mRNA and protein expression of HIF-1 controlled genes. Likewise, cell death induced by depletion of glutathione was decreased significantly by treatment with $\mathrm{CoCl}_{2}$ at a concentration $>200 \mu \mathrm{M}$, a competitive inhibitor of iron. $\mathrm{CoCl}_{2}$ also elevated the HIF- $1 \alpha$ protein expression.

Subsequently, several studies explored the ability of iron chelators for HIF-1 mediated neuroprotection against hypoxic injury. Siddiq et al. (2005) investigated the mechanism by which DFO offered protection in neuronal cells. In cortical neurons, HIF-1 $\alpha$ was stabilized upon treatment with $100 \mu \mathrm{M}$ DFO and protected cells from oxidative glutamate toxicity. Similarly, Prass et al. (2002) demonstrated the neuroprotective effect of DFO against OGD injury in purified cortical neurons. DFO at a concentration of $150 \mu \mathrm{M} / \mathrm{L}$ induced $47 \%$ reduction in cell death in primary cortical neurons subjected to OGD.

Compound $\mathrm{A}$ is a novel proprietary (Fibrogen Inc., United States) small molecule iron chelator. It stabilized HIF- $1 \alpha$ in cortical neurons and increased the expression of HIF-1 targeted genes at a concentration of $40 \mu \mathrm{M}$ (Siddiq et al., 2005). It also conferred protection against oxidative glutamate toxicity. In addition to its protective effect in in vitro studies, treatment with $100 \mathrm{mg} / \mathrm{kg}$ of compound A, stabilized HIF-1 in rat brain within $3 \mathrm{~h}$. It also reduced infarct volume by $67 \%$, compared to control littermates. In hippocampal neurons from newborn mice, pretreatment with $10 \mathrm{mM} / \mathrm{L}$ DFO decreased OGD induced cell death by $45 \%$ compared to the control group. The protection conferred by DFO diminished upon cell's transfection with anti-HIF-1 $\alpha$. This finding suggests that the protection by DFO is through HIF-1 $\alpha$ induction (Hamrick et al., 2005).

Prolyl hydroxylases isoforms differ in their expression patterns, tissue distribution, subcellular localization, and their ability to hydroxylate HIF-1 $\alpha$ (Siddiq et al., 2009). Based on these characteristics, Siddiq and co-workers hypothesized that the neuroprotection conferred by PHD inhibitors are PHD isoform-specific and independent of HIF-1. In this regard, they investigated the role of $\mathrm{PHD}$ and HIF isoforms in giving neuroprotection against normoxic oxidative death by the treatment of PHD inhibitors in primary rat neurons. When compared to a previous in vitro study carried out by Zaman et al. (1999), they observed something distinctive in this study. They noted that the prevention of normoxic oxidative neuronal death by DFO is through the inhibition of PHD1 and HIF-1 $\alpha$ doesn't have any role in this mechanism. They also noted that its HIF- $2 \alpha$, not HIF- $1 \alpha$ controls the sensitivity to normoxic oxidative neuronal death.

In comparison to adult CNS, the neonatal brain is highly sensitive to the availability of essential substrates. Treatment with $60 \mathrm{mg} / \mathrm{kg}$ of $\mathrm{CoCl}_{2}$ and $200 \mathrm{mg} / \mathrm{kg}$ of DFO increased the level of HIF- $1 \alpha$ protein in rat pups compared to the vehicleinjected controls (Bergeron et al., 2000). Compared with that in vehicle-injected controls, preconditioning with DFO and $\mathrm{CoCl}_{2} 24 \mathrm{~h}$ before hypoxia-ischemia gave 56 and $75 \%$ protection, respectively.

Desferrioxamine promoted the binding of HIF-1 to DNA and transcription of EPO in vivo. There was a 20-fold increase in DNA binding of HIF-1 upon DFO application. The tolerance induced by DFO was time and dosage-dependent (Prass et al., 2002). Expression of GLUT1 protein was elevated in rat brain by the treatment of $300 \mathrm{mg} / \mathrm{kg}$ of DFO. Brain lesion area and whole brain cell loss reduced upon treatment with DFO. Notably, DFO treatment didn't affect striatal lesion but provided a $20 \%$ reduction in cortical injury compared with the vehicle group. Likewise, there was a $62 \%$ decrease in thalamic shrinkage by the treatment of DFO in comparison with vehicle-treated animals. Neurological score and sensorimotor performances also improved upon treatment with DFO (Freret et al., 2006).

Deferasirox (DFR) is an orally administrated iron chelator and is in clinical use with high tolerance (Hatcher et al., 2009). As previously observed in the study by Siddiq et al. (2009); Zhao and Rempe (2011) also showed that neuroprotection conferred by DFO and DFR following MCAO does not require HIF- $1 \alpha$ in mice. They also observed that both DFO and DFR do not induce expression of HIF-1 target genes.

$2,2^{\prime}$-dipyridyl (DP) is a liposoluble iron chelator, and it is used to regulate HIF-1 $\alpha$ expression up. Experiments show that DP treatment reduced infarct volume and maximal infarct area and thus significantly decreased histological damage (Demougeot et al., 2004). There was a $42 \%$ reduction of infarct volume and a $25 \%$ decrease in the maximal infarct area upon treatment with DP. It protected both endothelial cells and neurons from ischemic injury. Besides, DP treatment in rats reduced ischemia-induced reactive oxygen species (ROS) production and suppressed the transformation of penumbra into infarct.

In chemical photothrombosis stroke models, DP treatment hindered the progression of infarct core and the surrounding regions (Hoecke et al., 2005). The density of apoptotic bodies reduced upon treatment with DP in both infarct core and surrounding pale region. Compared to the vehicletreated animals, DP treatment decreased and limited the DNA fragmentation only to $\mathrm{P} 1$ region. Upon treatment with DP, there was a significant reduction in procaspase- 9 cleavage in the P1 and P2 regions. Similarly, procaspase- 3 cleavage was decreased in these regions. There was also a drop in cleaved caspase- 3 in the entire infarct region upon treatment with DP in vivo.

Neuroprotection achieved by DP post-treatment was lower when compared with DP pretreatment (Baranova et al., 2007). Further, the protective effect produced through the administration of DP before or after MCAO was significantly attenuated but not completely abolished in neuron-specific 
HIF-1 $\alpha$-deficient mice. This shows the involvement of an alternative mechanism in giving neuroprotection upon DP treatment. Similarly, another study (Jones and Bergeron, 2001) observed that there was no change in expression of genes modulated by HIF-1 upon preconditioning with $\mathrm{CoCl}_{2}$ suggesting a surrogate process may be involved in the induction of tolerance by $\mathrm{CoCl}_{2}$ in the brain of newborn rats.

\section{OG Analogs}

Numerous hydroxybenzenes, hydroxybenzoic acids and analogous compounds have similar structural features as both 2-oxoglutarate and ascorbate. They can compete with these molecules and inhibit prolyl 4-hydroxylase enzymes (Majamaa et al., 1986). $10 \mu \mathrm{M}$ dihydroxybenzoic acid (DHB) stabilized HIF- $1 \alpha$ and increased the transcription of HIF-1 dependent genes. DHB conferred protection to cortical neurons exposed to oxidative glutamate toxicity (Siddiq et al., 2005).

$\mathrm{N}$-oxalylglycine can inhibit most of the 2OG-dependent oxygenases and other enzymes (Al-Qahtani et al., 2015). Dimethyloxalylglycine (DMOG) is a readily cell permeable ester of $\mathrm{N}$-oxalylglycine. DMOG has a similar structure to 2OG. It competes with PHD co-substrate, $2 \mathrm{OG}$ and prevents HIF-1 $\alpha$ degradation (Siddiq et al., 2009; Nagel et al., 2011). Twenty four hour treatment with DMOG increased the protein expression of HIF- $1 \alpha$ and mRNA levels of VEGF in cortical neurons growing under normoxic condition. Preconditioning with DMOG for 24 h before OGD significantly reduced OGD-induced cell death in cortical neuron cell. Similarly, post-treatment with DMOG also reduced cell death. This protection abrogated by the pretreatment of HIF-1 $\alpha$-shRNA showed the need of HIF-1 $\alpha$ for achieving neuroprotection using PHD inhibitors (Ogle et al., 2012).

In vivo stabilization of HIF-1 was observed within $6 \mathrm{~h}$ of administration of DHB. There was a significant reduction of infarct volume upon DHB treatment compared to control (Siddiq et al., 2005). Studies in mice showed that intraperitoneal injection of DMOG increased the level of HIF-1 $\alpha$ protein up to threefold in a time-dependent manner in mouse brain cortex. It also elevated the expression of HIF-1 controlled genes that regulate erythropoietin and pyruvate dehydrogenase kinase-1. Further, post-OGD treatment with DMOG reduced the infarct volume in an animal stroke model. In addition to this, it stimulated pro-apoptotic caspase- 3 protein, curtailed behavioral deficits and decreased the loss of local blood flow in the middle cerebral artery territory. These attributes nullified upon inhibition of HIF-1 $\alpha$ by Digoxin (Ogle et al., 2012).

In another study by Nagel et al. (2011), DMOG reduced ischemic injury and improved behavior and neuroscore after both permanent and transient MCAO in adult male Wistar rats. Regional cerebral blood flow also improved. There was also a reduction in the amount of $\mathrm{BBB}$ breakdown. A consistent increase in the expression of both mRNA and protein levels of VEGF and endothelial nitric oxide synthase observed after DMOG treatment. As seen in the case of DFO, a study by Siddiq and co-workers suggested that the neuroprotection exerted by DMOG and DHF does not require HIF-1 $\alpha$ stabilization and instead inhibit the PHD1 isoform (Siddiq et al., 2005).

\section{PHD Inhibitors With an Alternative Mechanism of Action}

This section also includes HIF-1 $\alpha$ stabilizers, but their exact mechanism of PHD inhibition is not either mentioned in the source paper or different from the above classification. These molecules may act by binding directly to the active site of the PHDs without mimicking 2OG or chelating the iron atom. A study (Reischl et al., 2014) focusing on reducing neuronal death following ischemic stroke via maintaining BBB integrity used a novel PHD inhibitor, FG-4497. HIF-1 $\alpha$ stabilized upon treatment with FG-4497 in both primary murine astrocytes and the murine cerebrovascular endothelial cell line. FG-4497's capability to inhibit HIF-1 $\alpha$ proteolysis was higher than DMOG. It also up-regulated the transcription of HIF-1 targeted genes VEGF and EPO. In mouse hippocampal culture, FG-4497 significantly enhanced the survival of cells following OGD.

Intraperitoneal injection of FG-4497 elevated the amount of HIF- $1 \alpha$ in cerebral tissue and significantly reduced infarct size compared to vehicle-treated mice (Reischl et al., 2014). FG-4497 pre-treatment reduces infarct volume in transient MCAO models. Post-treatment with FG-4497 also showed neuroprotection following permanent cerebral ischemia.

2-(1-chloro-4-hydroxyisoquinoline-3-carboxamido) acetic acid (IOX3) is a novel inhibitor of PHDs (Chen et al., 2014). It has a structure similar to FG2216, which promoted the expression of EPO in vivo. Administration of IOX3 24h before a MCAO

TABLE 1 | Details about the studies that used non-PHD HIF-1 $\alpha$ stabilizers as hypoxia-mimetic agents.

\begin{tabular}{|c|c|c|c|c|c|c|}
\hline SI. No. & Study & Compound(s) & Type of compound & $\begin{array}{l}\text { Time of } \\
\text { administration }\end{array}$ & $\begin{array}{l}\text { Stroke } \\
\text { model(s) }\end{array}$ & Cell/animal type \\
\hline 1 & Liu et al., 2015 & miR-335 & microRNA & $\begin{array}{l}\text { Immediately or } 24 \mathrm{~h} \\
\text { after MCAO }\end{array}$ & EMCAO & Male Wistar rats \\
\hline 2 & Li et al., 2008 & Isoflurane & Anesthetic & $24 \mathrm{~h}$ before OGD & OGD & Hippocampal neurons \\
\hline 3 & Li et al., 2012 & Isoflurane & & $\begin{array}{l}\text { Not specified } \\
\text { (post-OGD/MCAO) }\end{array}$ & OGD/MCAO & $\begin{array}{l}\text { Male Sprague-Dawley rats; } \\
\text { Primary cortical neurons }\end{array}$ \\
\hline 4 & Zhang Z. et al., 2014 & NAC & Antioxidant & 30 min before MCAO & MCAO & Male Sprague-Dawley rats \\
\hline 5 & Badawi and Shi, 2017 & $\begin{array}{l}\text { MG-132; } \\
\text { Epoxomicin }\end{array}$ & Proteasome inhibitor & 24 h before MCAO & OGD/MCAO & $\begin{array}{l}\text { C57/BL/6 male mice; } \\
\text { Primary cortical neurons }\end{array}$ \\
\hline 6 & Doeppner et al., 2012 & BSc2118 & Proteasome inhibitor & $12 \mathrm{~h}$ before MCAO & MCAO & Male C57BL/6N mice \\
\hline 7 & Ratan et al., 2008 & Tilorone & Antiviral agent & $24 \mathrm{~h}$ before $\mathrm{MCAO}$ & MCAO & Male Sprague-Dawley rats \\
\hline
\end{tabular}




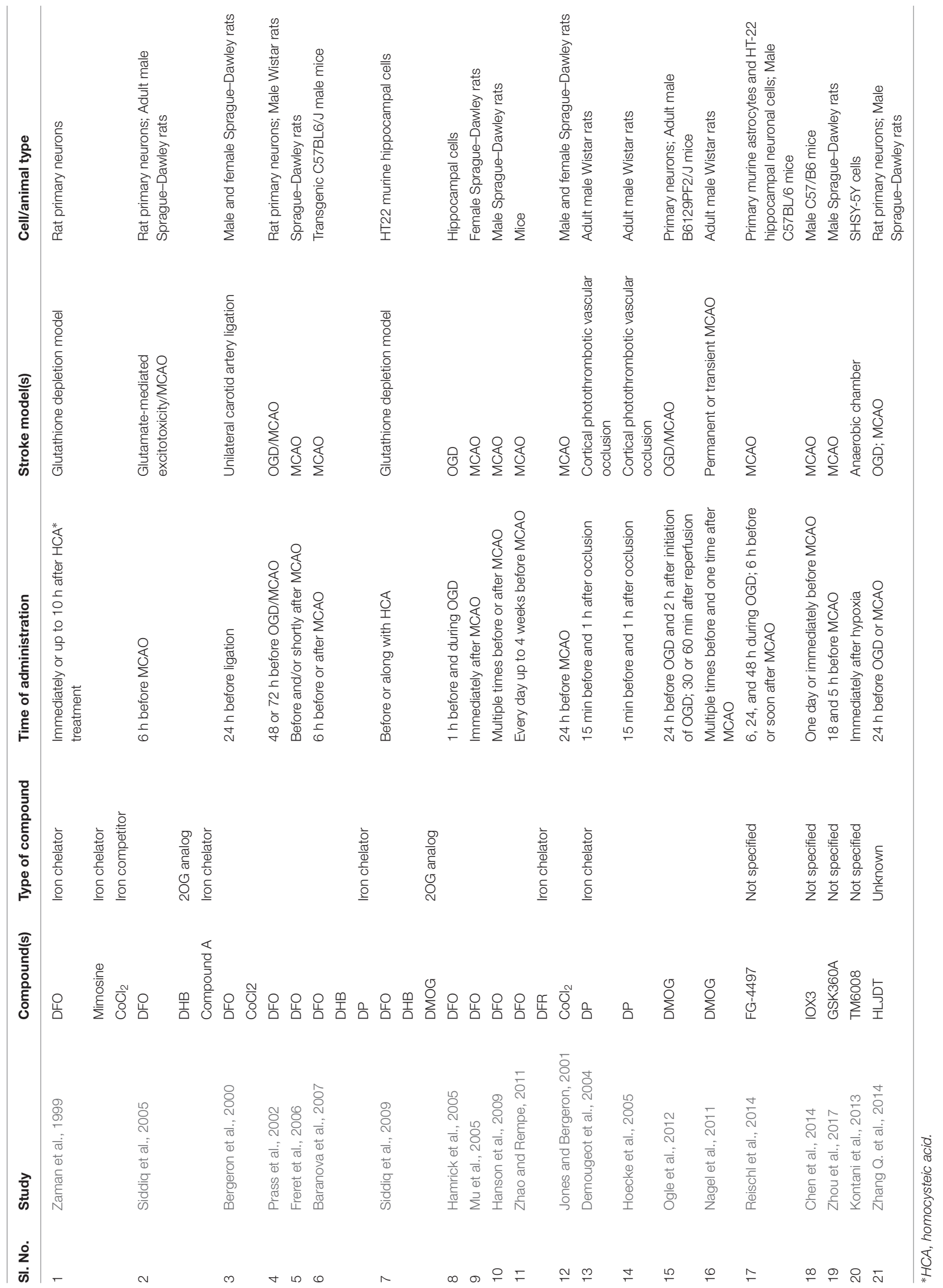


improved neuroscores and reduced infarct volume in mice. It also elevated the level of HIF-1 $\alpha$ protein and EPO expression. However, injection of IOX3 soon before the MCAO showed no significant neuroprotection. IOX3 also prevented BBB disruption when treated $24 \mathrm{~h}$ before MCAO.

GSK360A is an orally active PHD inhibitor that has reduced myocardial infarct size in the rat and murine heart (Ong et al., 2014). Treatment with GSK360A increased the plasma EPO and VEGF mRNA and protein levels (Zhou et al., 2017). When compared to the vehicle-treated group, pretreatment with GSK360A reduced post-stroke surgery neurological deficits, cognitive dysfunction and infarct volume 4 weeks after MCAO. Another novel PHD inhibitor, TM6008 decreased cell death and up-regulated HIF-1 $\alpha$ levels in vitro. It also induced the protein expression of HIF-1 downstream genes, HO-1, EPO, and glucose transporter 3 (GLUT3) (Kontani et al., 2013).

Lately, molecular docking and simulation studies carried out in our lab found folic acid (FA) to be an ideal compound that binds to PHD2, FIH and pVHL alike at their HIF- $1 \alpha$ binding region (Davis et al., 2018). In vitro experiments showed that postischemic treatment with FA up-regulated HIF-1 expression and its downstream genes. Further, FA conferred neuroprotection following OGD and promoted angiogenesis.

\section{HIF-1 $\alpha$ Up-Regulation Without the Inhibition of PHDs}

Non-PHD HIF-1 $\alpha$ stabilizers relay on a mechanism other than the classical PHD-HIF pathway to up-regulates HIF- $1 \alpha$. Compared to the conventional PHD inhibitors, these molecules are newly discovered. HIF- $1 \alpha$ stabilization through IPC is not discussed in this review as it is out of the scope of the title theme.

A study by Liu et al. (2015) showed that miR-335 is a direct regulator of HIF- $1 \alpha$, and has shown an inverse expression profile both in vivo and in vitro ischemic models. Treatment with miR335 decreased infarct volume immediately after MCAO, and miR-335 inhibitor was found to be beneficial at $24 \mathrm{~h}$ after MCAO in a rat model. Thus, regulation of HIF- $1 \alpha$ expression by miR335 at various time points manipulated the genes required for adaption to hypoxia and ultimately resulted in the reduction of infarct volume.

Preconditioning with $1.5 \%$ isoflurane protected neurons from oxygen-glucose deprivation (OGD) injury by the induction of HIF- $1 \alpha$ protein, and this activation is linked to the Erk1/2 pathway (Li et al., 2008). Further, a recent study by the above group showed the neuroprotection provided by isoflurane postconditioning via HIF-1 $\alpha$ stabilization (Li et al., 2012). Postischemic treatment with isoflurane reduced the infarct volume and improved neurological scores. Both post and pre-ischemic treatment with isoflurane treatment up-regulated iNOS mRNA level.

$\mathrm{N}$-acetylcysteine (NAC) has various therapeutic properties, and it is an antioxidant (Dhouib et al., 2016). It is also protected the brain from ischemic injury in preclinical studies (Zhang $\mathrm{Z}$. et al., 2014). A study by Zhang and colleagues observed that pretreatment with $150 \mathrm{mg} / \mathrm{kg}$ of NAC increased the protein levels of HIF-1 $\alpha$, EPO and GLUT3 in the ipsilateral hemispheres of rodents. The group also found out that HIF-1 is responsible for NAC mediated neuroprotection following MCAO. NAC treatment up-regulated heat shock protein 90 (Hsp90) expression and in turn interaction of Hsp90 to HIF-1.

A study by Badawi and Shi (2017) reported that 20S and 26S proteasomal pathways were involved in HIF-1 $\alpha$ degradation in ischemic neurons. For the in vitro studies, MG-132, a proteasome inhibitor was used and it stabilized HIF-1 $\alpha$ protein better than DMOG. A combination of MG-132 and DMOG had a better effect on HIF-1 $\alpha$ stabilization than them individually. Further, they observed that treatment with epoxomicin, another proteasome inhibitor reduced infarct size and brain oedema following oxidative stress in vivo by the stabilization of HIF$1 \alpha$. In vivo also a combination of epoxomicin and DMOG yielded better protection. The study also showed that proteasome inhibitors are more effective than PHD inhibitors in providing HIF- $1 \alpha$ stabilization and neuroprotection.

Doeppner et al. (2012) tested a novel proteasome inhibitor BSc2118 for its neuroprotective activity following ischemic stroke. $12 \mathrm{~h}$ pre-ischemic injection of BSc2118 conferred significant reduction of infarct volumes on day four. BSc2118 yielded long-term neuroprotection for as long as 3 months with the post-stroke treatment. Apart from reducing the infarct volume, BSc2118 was able to decrease brain oedema, and BBB break down. Further, it promoted both angiogenesis and neurogenesis. Using the knock out studies, they concluded that all these positive effects of BSc2118 were mediated by HIF- $1 \alpha$.

Tilorone is a low molecular weight antiviral agent (Ekins et al., 2017). In a study by Ratan et al. (2008) tilorone at a concentration of $100 \mathrm{mg} / \mathrm{kg}$ increased the stabilization of HIF- $1 \alpha$ and elevated the expression of its downstream genes in vitro. The stabilization of HIF- $1 \alpha$ by tilorone was independent of iron chelation and HIF-PHD inhibition in vitro. Tilorone also significantly reduced infarct volume in vivo following MCAO.

Huang-Lian-Jie-Du-Tang (HLJDT) is a traditional Chinese medicine with properties like heat-clearing and detoxification (Zhang Q. et al., 2014). In cerebral cortical neurons, pretreatment with HLJDT increased HIF-1 $\alpha$, EPO and VEGF levels and protected the cells against OGD. It decreased ischemia-induced apoptosis and promoted proliferation in neuronal cells. HLJDT also significantly reduced cerebral infarction; cerebral water content and improved neurological deficient score in MCAO rat models. All the hypoxia mimetic agents discussed in this review either act by inhibiting PHDs or other mechanisms and they ultimately regulate the expression of HIF-1. Tables 1, 2 gives a summary of the studies that used hypoxia-mimetic agents to obtain neuroprotection following ischemic injury.

\section{CONCLUSION}

Hypoxia causes the cell to accumulate HIF-1 in the nucleus and up-regulate specific HIF-1 targeted genes so that cells can overcome the adverse condition. All the hypoxia mimetic agents are designed to act in such a way to boost this endogenous mechanism. One way to do this is through the inhibition of 
PHDs. These PHD inhibitors come under either the iron chelator and competitive inhibitor category or the 2OG analog category. Other molecules rely on mechanisms other than PHD inhibition to stabilize HIF-1 $\alpha$. Apart from a few newly discovered molecules, widely used hypoxia-mimetic agents are $\mathrm{DFO}, \mathrm{DHB}, \mathrm{CoCl}_{2}$, DP, and DMOG. These agents up-regulated HIF-1 $\alpha$ levels and regulated its downstream genes.

Further, these agents conferred significant neuroprotection both in vitro and in vivo experiments. As the progression of ischemic brain injury is multifactorial, each of the HIF-1 regulated genes influences various cellular processes of infarct advancement at different time points. In most of the cases, treatment with hypoxia-mimetic agents several hours before or after the induction of hypoxia bestowed greater protection compared to treatment with these agents soon before or after oxidative stress. The neuroprotection conferred by these agents also depends on the cell type and magnitude of the ischemic injury.

However, there are studies which did not show neuroprotection via HIF-1 up-regulation and even demonstrated its pro-death features. Therefore, the extent of neuroprotection provided by HIF-1 in the case of ischemic injury is still a debatable topic. Nevertheless, in light of studies discussed in this review (Tables 1, 2); we can conclude that HIF-1's beneficial characteristics appear to outweigh its adverse effects. Many of the harmful effects of HIF- $1 \alpha$ can be eliminated by carefully choosing the time of administration of HIF-1 $\alpha$ stabilizers. Type of hypoxia

\section{REFERENCES}

Al-Qahtani, K., Jabeen, B., Sekirnik, R., Riaz, N., Claridge, T. D., Schofield, C. J., et al. (2015). The broad spectrum 2-oxoglutarate oxygenase inhibitor $\mathrm{N}$-oxalylglycine is present in rhubarb and spinach leaves. Phytochemistry 117, 456-461. doi: 10.1016/j.phytochem.2015.06.028

Aminova, L. R., Chavez, J. C., Lee, J., Ryu, H., Kung, A., Lamanna, J. C., et al. (2004). Prosurvival and prodeath effects of hypoxia-inducible factor- $1 \alpha$ stabilization in a murine hippocampal cell line. J. Biol. Chem. 280, 3996-4003. doi: 10.1074/jbc. m409223200

Appelhoff, R. J., Tian, Y.-M., Raval, R. R., Turley, H., Harris, A. L., Pugh, C. W., et al. (2004). Differential function of the Prolyl Hydroxylases PHD1, PHD2, and PHD3 in the regulation of hypoxia-inducible factor. J. Biol. Chem. 279, 38458-38465. doi: 10.1074/jbc.m406026200

Badawi, Y., and Shi, H. (2017). Relative contribution of rolyl Hydroxylasedependent and -independent degradation of HIF-1alpha by proteasomal pathways in cerebral ischemia. Front. Neurosci. 11:239. doi: 10.3389/fnins.2017. 00239

Baranova, O., Miranda, L. F., Pichiule, P., Dragatsis, I., Johnson, R. S., and Chavez, J. C. (2007). Neuron-specific inactivation of the hypoxia inducible factor 1 increases brain injury in a mouse model of transient focal cerebral ischemia. J. Neurosci. 27, 6320-6332. doi: 10.1523/jneurosci.0449-07.2007

Barteczek, P., Li, L., Ernst, A.-S., Böhler, L.-I., Marti, H. H., and Kunze, R. (2016). Neuronal HIF- $1 \alpha$ and HIF- $2 \alpha$ deficiency improves neuronal survival and sensorimotor function in the early acute phase after ischemic stroke. J. Cereb. Blood Flow Metab. 37, 291-306. doi: 10.1177/0271678x15624933

Beaudry, M., Hidalgo, M., Launay, T., Bello, V., and Darribère, T. (2016). Regulation of myogenesis by environmental hypoxia. J. Cell Sci. 129, 2887-2896. doi: $10.1242 /$ jcs. 188904

Bergeron, M., Gidday, J. M., Yu, A. Y., Semenza, G. L., Ferriero, D. M., and Sharp, F. R. (2000). Role of hypoxia-inducible factor-1 in hypoxiainduced ischemic tolerance in neonatal rat brain. Ann. Neurol. 48, 285-296. doi: 10.1002/1531-8249(200009)48:3<285::AID-ANA2>3.0.CO;2-8 mimetic agent used, nature of ischemic injury and kind of cell targeted by the treatment are the other factors which affect the neuroprotection bestowed by HIF-1 $\alpha$ stabilizers.

One drawback of using the conventional mimetic agent is that several other enzymes use $\mathrm{Fe}^{2+}$ and $2 \mathrm{OG}$ as co-factor or cosubstrate. Therefore the use of iron chelators, competitive iron inhibitors and 2OG analogs can create undesired interference of different pathways. In this regard, the introductions of novel drugs that can specifically inhibit PHDs or stabilize HIF-1 $\alpha$ through other mechanisms need more consideration. Specificity of PHD inhibitors can be achieved by the development of molecules that can bind to the active sites in PHDs. These agents could be analogous to the parts of HIF-1 $\alpha$ that interact with PHDs. The possibility of stabilizing HIF-1 $\alpha$ via FIH inhibition has not received much attention and warrants further exploration.

\section{AUTHOR CONTRIBUTIONS}

GR and AM conceived the idea. CD wrote the manuscript. SJ, GR, $\mathrm{AM}$, and $\mathrm{O}-\mathrm{NB}$ helped to draft the manuscript.

\section{FUNDING}

AM is funded by MRC grant (reference no: MR/R005923/1).

Bernaudin, M., Tang, Y., Reilly, M., Petit, E., and Sharp, F. R. (2002). Brain genomic response following hypoxia and re-oxygenation in the neonatal rat. J. Biol. Chem. 277, 39728-39738. doi: 10.1074/jbc.m204619200

Bok, S., Kim, Y.-E., Woo, Y., Kim, S., Kang, S.-J., Lee, Y., et al. (2017). Hypoxiainducible factor- $1 \alpha$ regulates microglial functions affecting neuronal survival in the acute phase of ischemic stroke in mice. Oncotarget 8, 111508-111521. doi: 10.18632 /oncotarget.22851

Chavez, J. C., and Lamanna, J. C. (2002). Activation of hypoxia-inducible factor1 in the rat cerebral cortex after transient global ischemia: potential role of insulin-like growth factor-1. J. Neurosci. 22, 8922-8931. doi: 10.1523/jneurosci. 22-20-08922.2002

Chen, C., Hu, Q., Yan, J., Lei, J., Qin, L., Shi, X., et al. (2007). Multiple effects of $2 \mathrm{ME} 2$ and D609 on the cortical expression of HIF-1 $\alpha$ and apoptotic genes in a middle cerebral artery occlusion induced focal ischemia rat model. J. Neurochem. 102, 1831-1841. doi: 10.1111/j.1471-4159.2007.004652.x

Chen, C., Hu, Q., Yan, J., Yang, X., Shi, X., Lei, J., et al. (2009). Early inhibition of HIF-1 $\alpha$ with small interfering RNA reduces ischemic-reperfused brain injury in rats. Neurobiol. Dis. 33, 509-517. doi: 10.1016/j.nbd.2008.12.010

Chen, H., Xiong, T., Qu, Y., Zhao, F., Ferriero, D., and Mu, D. (2012). mTOR activates hypoxia-inducible factor- $1 \alpha$ and inhibits neuronal apoptosis in the developing rat brain during the early phase after hypoxia-ischemia. Neurosci. Lett. 507, 118-123. doi: 10.1016/j.neulet.2011.11.058

Chen, R. L., Ogunshola, O. O., Yeoh, K. K., Jani, A., Papadakis, M., Nagel, S., et al. (2014). HIF prolyl hydroxylase inhibition prior to transient focal cerebral ischaemia is neuroprotective in mice. J. Neurochem. 131, 177-189. doi: 10.1111/ jnc. 12804

Chen, W., Jadhav, V., Tang, J., and Zhang, J. H. (2008). HIF-1 alpha inhibition ameliorates neonatal brain damage after hypoxic-ischemic injury. Acta Neurochir. Suppl. 102, 395-399. doi: 10.1007/978-3-211-85 578-2_77

Chen, W., Ostrowski, R. P., Obenaus, A., and Zhang, J. H. (2009). Prodeath or prosurvival: two facets of hypoxia inducible factor- 1 in perinatal brain injury. Exp. Neurol. 216, 7-15. doi: 10.1016/j.expneurol.2008.10.016 
Davis, C. K., Nampoothiri, S. S., and Rajanikant, G. K. (2018). Folic acid exerts postischemic neuroprotection in vitro through HIF-1 $\alpha$ stabilization. Mol. Neurobiol. 55, 8328-8345. doi: 10.1007/s12035-018-0982-3

Demougeot, C., Van Hoecke, M., Bertrand, N., Prigent-Tessier, A., Mossiat, C., Beley, A., et al. (2004). Cytoprotective efficacy and mechanisms of the liposoluble iron chelator 2, 2'-dipyridyl in the rat photothrombotic ischemic stroke model. J. Pharmacol. Exp. Ther. 311, 1080-1087. doi: 10.1124/jpet.104. 072744

Dhouib, I. E., Jallouli, M., Annabi, A., Gharbi, N., Elfazaa, S., and Lasram, M. M. (2016). A minireview on $\mathrm{N}$-acetylcysteine: an old drug with new approaches. Life Sci. 151, 359-363. doi: 10.1016/j.lfs.2016.03.003

Doeppner, T. R., Mlynarczuk-Bialy, I., Kuckelkorn, U., Kaltwasser, B., Herz, J., Hasan, M. R., et al. (2012). The novel proteasome inhibitor BSc2118 protects against cerebral ischaemia through HIF1A accumulation and enhanced angioneurogenesis. Brain 135, 3282-3297. doi: 10.1093/brain/ aws 269

Ekins, S., Lingerfelt, M. A., Comer, J. E., Freiberg, A. N., Mirsalis, J. C., Oloughlin, K., et al. (2017). Efficacy of tilorone dihydrochloride against ebola virus infection. Antimicrob. Agents Chemother. 62, e1711-e1717. doi: 10.1128/ aac.01711- 17

Fan, X., Heijnen, C. J., Kooij, M. A. V. D., Groenendaal, F., and Bel, F. V. (2009). The role and regulation of hypoxia-inducible factor- $1 \alpha$ expression in brain development and neonatal hypoxic-ischemic brain injury. Brain Res. Rev. 62, 99-108. doi: 10.1016/j.brainresrev.2009.09.006

Fandrey, J., Gorr, T., and Gassmann, M. (2006). Regulating cellular oxygen sensing by hydroxylation. Cardiovasc. Res. 71, 642-651. doi: 10.1016/j.cardiores.2006. 05.005

Fisher, S. A., Brunskill, S. J., Doree, C., Gooding, S., Chowdhury, O., and Roberts, D. J. (2013). Desferrioxamine mesylate for managing transfusional iron overload in people with transfusion-dependent thalassaemia. Cochrane Database Syst. Rev. 21:CD004450. doi: 10.1002/14651858.cd004450.pub3

Freret, T., Valable, S., Chazalviel, L., Saulnier, R., Mackenzie, E. T., Petit, E., et al. (2006). Delayed administration of deferoxamine reduces brain damage and promotes functional recovery after transient focal cerebral ischemia in the rat. Eur. J. Neurosci. 23, 1757-1765. doi: 10.1111/j.1460-9568.2006. 04699.x

Guo, S., Bragina, O., Xu, Y., Cao, Z., Chen, H., Zhou, B., et al. (2008). Glucose upregulates HIF- $1 \alpha$ expression in primary cortical neurons in response to hypoxia through maintaining cellular redox status. J. Neurochem. 105, 1849-1860. doi: $10.1111 /$ j.1471-4159.2008.05287.x

Guo, Y. (2017). Role of HIF-1a in regulating autophagic cell survival during cerebral ischemia reperfusion in rats. Oncotarget 8, 98482-98494. doi: 10.18632/ oncotarget. 21445

Halterman, M. W., Miller, C. C., and Federoff, H. J. (1999). Hypoxia-inducible factor- $1 \alpha$ mediates hypoxia-induced delayed neuronal death that involves p53. J. Neurosci. 19, 6818-6824. doi: 10.1523/jneurosci.19-16-06818.1999

Hamrick, S. E. G., Mcquillen, P. S., Jiang, X., Mu, D., Madan, A., and Ferriero, D. M. (2005). A role for hypoxia-inducible factor- $1 \alpha$ in desferoxamine neuroprotection. Neurosci. Lett. 379, 96-100. doi: 10.1016/j.neulet.2004. 12.080

Hanson, L. R., Roeytenberg, A., Martinez, P. M., Coppes, V. G., Sweet, D. C., Rao, R. J., et al. (2009). Intranasal deferoxamine provides increased brain exposure and significant protection in rat ischemic stroke. J. Pharmacol. Exp. Ther. 330, 679-686. doi: 10.1124/jpet.108.149807

Harten, S. K., Ashcroft, M., and Maxwell, P. H. (2010). Prolyl hydroxylase domain inhibitors: a route to HIF activation and neuroprotection. Antioxid. Redox Signal. 12, 459-480. doi: 10.1089/ars.2009.2870

Hatcher, H. C., Singh, R. N., Torti, F. M., and Torti, S. V. (2009). Synthetic and natural iron chelators: therapeutic potential and clinical use. Future Med. Chem. 1, 1643-1670. doi: 10.4155/fmc.09.121

Helton, R., Cui, J., Scheel, J. R., Ellison, J. A., Ames, C., Gibson, C., et al. (2005). Brain-specific knock-out of hypoxia-inducible factor-1 reduces rather than increases hypoxic-ischemic damage. J. Neurosci. 25, 4099-4107. doi: 10.1523/ jneurosci.4555-04.2005

Hoecke, M. V., Prigent-Tessier, A., Bertrand, N., Prevotat, L., Marie, C., and Beley, A. (2005). Apoptotic cell death progression after photothrombotic focal cerebral ischaemia: effects of the lipophilic iron chelator $2,2^{\prime}$-dipyridyl. Eur. J. Neurosci. 22, 1045-1056. doi: 10.1111/j.1460-9568.2005.04297.x
Hoecke, M. V., Prigent-Tessier, A. S., Garnier, P. E., Bertrand, N. M., Filomenko, R., Bettaieb, A., et al. (2007). Evidence of HIF-1 functional binding activity to caspase-3 promoter after photothrombotic cerebral ischemia. Mol. Cell. Neurosci. 34, 40-47. doi: 10.1016/j.mcn.2006.09.009

Hu, C.-J., Wang, L.-Y., Chodosh, L. A., Keith, B., and Simon, M. C. (2003). Differential roles of Hypoxia-Inducible Factor 1 (HIF-1) and HIF-2 in hypoxic gene regulation. Mol. Cell. Biol. 23, 9361-9374. doi: 10.1128/mcb.23.24.93619374.2003

Jablonska, B., Gierdalski, M., Chew, L.-J., Hawley, T., Catron, M., Lichauco, A., et al. (2016). Sirt1 regulates glial progenitor proliferation and regeneration in white matter after neonatal brain injury. Nat. Commun. 7:13866. doi: 10.1038/ ncomms 13866

Jones, N. M., and Bergeron, M. (2001). Hypoxic preconditioning induces changes in HIF-1 target genes in neonatal rat brain. J. Cereb. Blood Flow Metab. 21, 1105-1114. doi: 10.1097/00004647-200109000-00008

Karuppagounder, S. S., and Ratan, R. R. (2012). Hypoxia-inducible factor prolyl hydroxylase inhibition: robust new target or another big bust for stroke therapeutics? J. Cereb. Blood Flow Metab. 32, 1347-1361. doi: 10.1038/jcbfm. 2012.28

Kim, A. S., and Johnston, S. C. (2013). Temporal and geographic trends in the global stroke epidemic. Stroke 44, S123-S125. doi: 10.1161/strokeaha.111. 000067

Kontani, S., Nagata, E., Uesugi, T., Moriya, Y., Fujii, N., Miyata, T., et al. (2013). A novel prolyl hydroxylase inhibitor protects against cell death after hypoxia. Neurochem. Res. 38, 2588-2594. doi: 10.1007/s11064-013-1175-0

Koronowski, K., and Perez-Pinzon, M. (2015). Sirt1 in cerebral ischemia. Brain Circ. 1, 69-78. doi: 10.4103/2394-8108.162532

Li, L., Saliba, P., Reischl, S., Marti, H. H., and Kunze, R. (2016). Neuronal deficiency of HIF prolyl 4-hydroxylase 2 in mice improves ischemic stroke recovery in an HIF dependent manner. Neurobiol. Dis. 91, 221-235. doi: 10.1016/j.nbd.2016. 03.018

Li, Q. F., Xu, H., Sun, Y., Hu, R., and Jiang, H. (2012). Induction of inducible nitric oxide synthase by isoflurane post-conditioning via hypoxia inducible factor$1 \alpha$ during tolerance against ischemic neuronal injury. Brain Res. 1451, 1-9. doi: 10.1016/j.brainres.2012.02.055

Li, Q.-F., Zhu, Y.-S., and Jiang, H. (2008). Isoflurane preconditioning activates HIF$1 \alpha, \mathrm{iNOS}$ and Erk1/2 and protects against oxygen-glucose deprivation neuronal injury. Brain Res. 1245, 26-35. doi: 10.1016/j.brainres.2008.09.069

Liu, F. J., Kaur, P., Karolina, D. S., Sepramaniam, S., Armugam, A., Wong, P. T. H., et al. (2015). MiR-335 regulates Hif- $1 \alpha$ to reduce cell death in both mouse cell line and rat ischemic models. PLoS One 10:e0128432. doi: 10.1371/journal.pone. 0128432

Liu, M., and Alkayed, N. J. (2005). Hypoxic preconditioning and tolerance via Hypoxia Inducible Factor (HIF) $1 \alpha$-linked induction of P450 2C11 epoxygenase in astrocytes. J. Cereb. Blood Flow Metab. 25, 939-948. doi: 10.1038/sj.jcbfm. 9600085.a

Liu, W., Shen, S.-M., Zhao, X.-Y., and Chen, G.-Q. (2012). Targeted genes and interacting proteins of hypoxia inducible factor-1. Int. J. Biochem. Mol. Biol. 3, 165-178.

Majamaa, K., Günzler, V., Hanauske-Abel, H. M., Myllylä, R., and Kivirikko, K. I. (1986). Partial identity of the 2-oxoglutarate and ascorbate binding sites of prolyl 4-hydroxylase. J. Biol. Chem. 261, 7819-7823.

Masoud, G. N., and Li, W. (2015). HIF-1 $\alpha$ pathway: role, regulation and intervention for cancer therapy. Acta Pharm. Sin. B 5, 378-389. doi: 10.1016/ j.apsb.2015.05.007

Mayhan, W. G. (1999). VEGF increases permeability of the blood-brain barrier via a nitric oxide synthase/cGMP-dependent pathway. Am. J. Physiol Cell Physiol. 276, C1148-C1153. doi: 10.1152/ajpcell.1999.276.5.c1148

Michel, L. Y. M., Verkaart, S., Koopman, W. J. H., Willems, P. H. G. M., Hoenderop, J. G. J., and Bindels, R. J. M. (2014). Function and regulation of the $\mathrm{Na}-\mathrm{Ca} 2$ exchanger NCX3 splice variants in brain and skeletal muscle. J. Biol. Chem. 289, 11293-11303. doi: 10.1074/jbc.m113.529388

Min, J.-W., Hu, J.-J., He, M., Sanchez, R. M., Huang, W.-X., Liu, Y.-Q., et al. (2015). Vitexin reduces hypoxia-ischemia neonatal brain injury by the inhibition of HIF-1alpha in a rat pup model. Neuropharmacology 99, 38-50. doi: 10.1016/j. neuropharm.2015.07.007

Mu, D., Jiang, X., Sheldon, R., Fox, C. K., Hamrick, S. E., Vexler, Z. S., et al. (2003). Regulation of hypoxia-inducible factor $1 \alpha$ and induction of vascular 
endothelial growth factor in a rat neonatal stroke model. Neurobiol. Dis. 14, 524-534. doi: 10.1016/j.nbd.2003.08.020

Mu, D., Chang, Y. S., Vexler, Z. S., and Ferriero, D. M. (2005). Hypoxia-inducible factor $1 \alpha$ and erythropoietin upregulation with deferoxamine salvage after neonatal stroke. Exp. Neurol. 195, 407-415. doi: 10.1016/j.expneurol.2005. 06.001

Na, Y.-R., Woo, D. J., Choo, H., Chung, H. S., and Yang, E. G. (2015). Selective inhibition of the hypoxia-inducible factor prolyl hydroxylase PHD3 by $\mathrm{Zn}$ (ii). Chem. Commun. 51, 10730-10733. doi: 10.1039/c5cc02143j

Nagel, S., Papadakis, M., Chen, R., Hoyte, L. C., Brooks, K. J., Gallichan, D., et al. (2011). Neuroprotection by dimethyloxalylglycine following permanent and transient focal cerebral ischemia in rats. J. Cereb. Blood Flow Metab. 31, 132-143. doi: 10.1038/jcbfm.2010.60

Ogle, M. E., Gu, X., Espinera, A. R., and Wei, L. (2012). Inhibition of prolyl hydroxylases by dimethyloxaloylglycine after stroke reduces ischemic brain injury and requires hypoxia inducible factor-1 $\alpha$. Neurobiol. Dis. 45, 733-742. doi: 10.1016/j.nbd.2011.10.020

Ong, S.-G., Lee, W. H., Theodorou, L., Kodo, K., Lim, S. Y., Shukla, D. H., et al. (2014). HIF-1 reduces ischaemia-reperfusion injury in the heart by targeting the mitochondrial permeability transition pore. Cardiovasc. Res. 104, 24-36. doi: $10.1093 / \mathrm{cvr} / \mathrm{cvu} 172$

Peyssonnaux, C., Nizet, V., and Johnson, R. S. (2008). Role of the hypoxia inducible factors HIF in iron metabolism. Cell Cycle 7, 28-32. doi: 10.4161/cc.7.1.5145

Prass, K., Ruscher, K., Karsch, M., Isaev, N., Megow, D., Priller, J., et al. (2002). Desferrioxamine induces delayed tolerance against cerebral ischemia in vivo and in vitro. J. Cereb. Blood Flow Metab. 22, 520-525. doi: 10.1097/00004647200205000-00003

Ratan, R. R., Siddiq, A., Aminova, L., Langley, B., Mcconoughey, S., Karpisheva, K., et al. (2008). Small molecule activation of adaptive gene expression. Ann. N. Y. Acad. Sci. 1147, 383-394. doi: 10.1196/annals.1427.033

Ratcliffe, P. J. (2007). HIF-1 and HIF-2: working alone or together in hypoxia? J. Clin. Investig. 117, 862-865. doi: 10.1172/jci31750

Reischl, S., Li, L., Walkinshaw, G., Flippin, L. A., Marti, H. H., and Kunze, R. (2014). Inhibition of HIF prolyl-4-hydroxylases by FG-4497 reduces brain tissue injury and edema formation during ischemic stroke. PLoS One 9:e84767. doi: 10.1371 /journal.pone.0084767

Schofield, C. J., and Ratcliffe, P. J. (2004). Oxygen sensing by HIF hydroxylases. Nat. Rev. Mol. Cell Biol. 5, 343-354. doi: 10.1038/nrm1366

Schofield, C. J., and Zhang, Z. (1999). Structural and mechanistic studies on 2oxoglutarate-dependent oxygenases and related enzymes. Curr. Opin. Struct. Biol. 9, 722-731. doi: 10.1016/s0959-440x(99)00036-6

Semenza, G. L. (1998). Hypoxia-inducible factor 1: master regulator of O2 homeostasis. Curr. Opin. Genet. Dev. 8, 588-594. doi: 10.1016/s0959-437x(98) 80016-6

Semenza, G. L. (2000). HIF-1: mediator of physiological and pathophysiological responses to hypoxia. J. Appl. Physiol. 88, 1474-1480. doi: 10.1152/jappl.2000. 88.4.1474

Semenza, G. L. (2001). Hypoxia-inducible factor 1: oxygen homeostasis and disease pathophysiology. Trends Mol. Med. 7, 345-350. doi: 10.1016/s1471-4914(01) 02090- 1

Semenza, G. L. (2014). Hypoxia-inducible factor 1 and cardiovascular disease. Annu. Rev. Physiol. 76, 39-56. doi: 10.1146/annurev-physiol-021113-170322

Shi, H. (2009). Hypoxia inducible factor 1 as a therapeutic target in ischemic stroke. Curr. Med. Chem. 16, 4593-4600. doi: 10.2174/092986709789760779

Siddiq, A., Aminova, L. R., Troy, C. M., Suh, K., Messer, Z., Semenza, G. L., et al. (2009). Selective inhibition of Hypoxia-Inducible Factor (HIF) prolylhydroxylase 1 mediates neuroprotection against normoxic oxidative death via HIF- and CREB-independent pathways. J. Neurosci. 29, 8828-8838. doi: 10.1523/jneurosci.1779-09.2009

Siddiq, A., Ayoub, I. A., Chavez, J. C., Aminova, L., Shah, S., Lamanna, J. C., et al. (2005). Hypoxia-inducible factor prolyl 4-hydroxylase inhibition. J. Biol. Chem. 280, 41732-41743. doi: 10.1074/jbc.m504963200

Simon, M. C., and Keith, B. (2008). The role of oxygen availability in embryonic development and stem cell function. Nat. Rev. Mol. Cell Biol. 9, 285-296. doi: $10.1038 / \mathrm{nrm} 2354$

Singh, N., Sharma, G., Mishra, V., and Raghubir, R. (2012). Hypoxia inducible factor-1: its potential role in cerebral ischemia. Cell. Mol. Neurobiol. 32, 491-507. doi: 10.1007/s10571-012-9803-9
Speer, R. E., Karuppagounder, S. S., Basso, M., Sleiman, S. F., Kumar, A., Brand, D., et al. (2013). Hypoxia-inducible factor prolyl hydroxylases as targets for neuroprotection by "antioxidant" metal chelators: from ferroptosis to stroke. Free Radic. Biol. Med. 62, 26-36. doi: 10.1016/j.freeradbiomed.2013.01.026

Vadlapatla, R., Vadlapudi, A., and Mitra, A. (2013). Hypoxia-Inducible Factor-1 (HIF-1): a potential target for intervention in ocular neovascular diseases. Curr. Drug Targets 14, 919-935. doi: 10.2174/13894501113149990015

Valsecchi, V., Pignataro, G., Prete, A. D., Sirabella, R., Matrone, C., Boscia, F., et al. (2011). NCX1 Is a novel target gene for hypoxia-inducible factor-1 in ischemic brain preconditioning. Stroke 42, 754-763. doi: 10.1161/strokeaha.110. 597583

Vangeison, G., Carr, D., Federoff, H. J., and Rempe, D. A. (2008). The good, the bad, and the cell type-specific roles of hypoxia inducible factor-1 in neurons and astrocytes. J. Neurosci. 28, 1988-1993. doi: 10.1523/jneurosci.5323-07. 2008

Wang, X., Ma, J., Fu, Q., Zhu, L., Zhang, Z., Zhang, F., et al. (2017). Role of hypoxia-inducible factor- $1 \alpha$ in autophagic cell death in microglial cells induced by hypoxia. Mol. Med. Rep. 15, 2097-2105. doi: 10.3892/mmr.2017.6277

Yang, Y., Ju, J., Deng, M., Wang, J., Liu, H., Xiong, L., et al. (2017). Hypoxia inducible factor $1 \alpha$ promotes endogenous adaptive response in rat model of chronic cerebral hypoperfusion. Int. J. Mol. Sci. 18:3. doi: 10.3390/ijms180 10003

Yeh, S.-H., Ou, L.-C., Gean, P.-W., Hung, J.-J., and Chang, W.-C. (2010). Selective inhibition of early-but not late-expressed HIF-1 $\alpha$ is neuroprotective in rats after focal ischemic brain damage. Brain Pathol. 21, 249-262. doi: 10.1111/j.17503639.2010.00443.x

Yoon, M.-S. (2017). The role of mammalian target of rapamycin (mTOR) in insulin signaling. Nutrients 9:1176. doi: 10.3390/nu9111176

Zaman, K., Ryu, H., Hall, D., Odonovan, K., Lin, K.-I., Miller, M. P., et al. (1999). Protection from oxidative stress-induced apoptosis in cortical neuronal cultures by iron chelators is associated with enhanced DNA binding of hypoxiainducible factor- 1 and ATF-1/CREB and increased expression of glycolytic enzymes, p21waf1/cip1, and erythropoietin. J. Neurosci. 19, 9821-9830. doi: 10.1523/jneurosci.19-22-09821.1999

Zeng, H.-L., Zhong, Q., Qin, Y.-L., Bu, Q.-Q., Han, X.-A., Jia, H.-T., et al. (2011). Hypoxia-mimetic agents inhibit proliferation and alter the morphology of human umbilical cord-derived mesenchymal stem cells. BMC Cell Biol. 12:32. doi: 10.1186/1471-2121-12-32

Zhang, Q., Bian, H., Li, Y., Guo, L., Tang, Y., and Zhu, H. (2014). Preconditioning with the traditional Chinese medicine Huang-Lian-Jie-DuTang initiates HIF-1 $\alpha$-dependent neuroprotection against cerebral ischemia in rats. J. Ethnopharmacol. 154, 443-452. doi: 10.1016/j.jep.2014.04.022

Zhang, Z., Yan, J., Taheri, S., Liu, K. J., and Shi, H. (2014). Hypoxia-inducible factor 1 contributes to N-acetylcysteine's protection in stroke. Free Radic. Biol. Med. 68, 8-21. doi: 10.1016/j.freeradbiomed.2013.11.007

Zhao, Y., and Rempe, D. A. (2011). Prophylactic neuroprotection against stroke: low-dose, prolonged treatment with deferoxamine or deferasirox establishes prolonged neuroprotection independent of HIF-1 function. J. Cereb. Blood Flow Metab. 31, 1412-1423. doi: 10.1038/jcbfm.2010.230

Zhou, D., Matchett, G. A., Jadhav, V., Dach, N., and Zhang, J. H. (2008). The effect of 2-methoxyestradiol, a HIF-1 $\alpha$ inhibitor, in global cerebral ischemia in rats. Neurol. Res. 30, 268-271. doi: 10.1179/016164107x229920

Zhou, J., Li, J., Rosenbaum, D. M., Zhuang, J., Poon, C., Qin, P., et al. (2017). The prolyl 4-hydroxylase inhibitor GSK360A decreases post-stroke brain injury and sensory, motor, and cognitive behavioral deficits. PLoS One 12:e0184049. doi: 10.1371/journal.pone.0184049

Conflict of Interest Statement: The authors declare that the research was conducted in the absence of any commercial or financial relationships that could be construed as a potential conflict of interest.

Copyright (C) 2019 Davis, Jain, Bae, Majid and Rajanikant. This is an open-access article distributed under the terms of the Creative Commons Attribution License (CC BY). The use, distribution or reproduction in other forums is permitted, provided the original author(s) and the copyright owner(s) are credited and that the original publication in this journal is cited, in accordance with accepted academic practice. No use, distribution or reproduction is permitted which does not comply with these terms. 